\title{
Metrology in Gas Analysis at the Federal Office of Metrology METAS
}

\author{
Bernhard Niederhauser*
}

\begin{abstract}
Gas analysis as a metrological discipline has a history of about 25 years in Switzerland. Starting with the requirement of reliable reference gas mixtures for legal applications the Swiss Federal Office of Metrology (METAS) had to increasingly find also calibration solutions for the ambient air level. Thereby the metrological principles of traceability, uncertainty evaluation and verification as well as the use of unambiguous terminology for quantities and units were in the focus of the activities. Using three examples different ways of implementing these principles are explained. For the emission range, traceability is mainly achieved by gravimetrically prepared certified gas mixtures in pressurised cylinders using high purity gases and a highly reproducible comparison method. The reactivity and limited stability of the important analytes in the ambient range ask for dynamic methods to secure traceability to the international system of units (SI). The dynamic methods requiring additionally high accuracy gas flow measurement techniques and trace gas analysis will be the focus for further developments at METAS.
\end{abstract}

Keywords: Gas analysis · Measurement uncertainty · Reference gas mixtures · Traceability · Verification

\section{Introduction}

The metrology community became interested already in the early 1980 s in gas analysis as the first field of chemical analysis at national metrology institutes (NMIs). The reason why gas analysis was the first field of quantitative chemical analysis is not very surprising. On one hand there was a strong pressure from a reactivated awareness for air pollution problems and the related political measures taken by the governments of highly affected as well as forward-looking countries. On the other hand in metrology - a branch of science dominated by physicists and engineers the experts were convinced that they could apply metrological principles also to quan-

${ }^{*}$ Correspondence: B. Niederhauser Federal Office of Metrology METAS Section Analytical Chemistry

Gas Analysis Laboratory

Lindenweg 50

$\mathrm{CH}-3084$ Bern-Wabern

Tel.: +41313233262

Fax: + 41313233210

E-mail: bernhard.niederhauser@metas.ch titative gas analysis and hence to support the quality and the reliability of measurement results that would form the basis of increasingly expensive and far-ranging actions and decisions.

This development of activities took also place at the Federal Office of Metrology METAS. There are several approaches to improve and guarantee a quality fit for the intended purpose, as will be outlined in the three examples in Section 4. The economically limited possibilities of metrology in Switzerland as well as the quality targets for the different tasks had to result in efficient and cost effective solutions in order to keep measurement quality issues out of the discussion focus.

Despite the fact that the ambient air quality in Switzerland has substantially improved during the last two decades, there are still substances or groups of substances that are exceeding the actual limits. In parallel the quality of measurement results as evaluated by national interlaboratory comparison tests has improved. [1] In order to maintain the high credibility of the measured and published data it is necessary to keep the efforts for quality assurance and to further promote the need for traceable, well validated values with known uncertainties reported in an understandable and correct form. This is all the more significant in view of the recently updated European directive on ambient air quality and cleaner air for Europe which includes not only a broader spectrum of analytes but also very clearly states the data quality targets expressed in terms of measurement uncertainty and traceability and the accreditation status for national laboratories acting as air quality data providers. ${ }^{[2]}$

\section{Historical Aspects and Motivation}

The demand for reliable results for the measurement of gaseous analytes and therefore for the respective gas mixture standards grew with the Swiss national programmes for air pollution control, in particular for the control of exhaust gases from combustion engines and domestic heaters. ${ }^{[3,4]}$ In 1984 the Swiss Federal Office of Metrology initiated its activity in the field of metrology in gas analysis by setting up a program for the qualification of exhaust gas analysers for combustion engines. The result of this imitative was one of the first regulations for exhaust gas analysers in Europe in 1985 and the related conformity assessment work for exhaust gas analysers. ${ }^{[5]}$ Two years after the vehicle exhaust ordinance, the directive fixing the requirements for heating plants measuring instruments and the according type approval were set up in accordance with the recommendation of the Federal Office for the Environment (FOEN) for the measurements of emissions from domestic heaters. $[6,7]$

To support the quality assurance of the already existing producers of gas mixture standards in Switzerland, METAS undertook a big effort to setup sets of high quality gas mixtures and the infrastructure to be able to compare in an automatic procedure the gas mixture standards produced by the Swiss manufacturers in order to build a national reference. ${ }^{[8]}$ The commercial certified gas mixtures traceable to national references were mainly used for type approval activities and increasingly for the calibration and verification of gas emis- 
sion instruments as a mean to maintain the metrological quality.

In the same context of the air pollution control initiative also the demand for calibration services for analytes, whose mixtures are unstable and therefore unsuitable for storage in gas cylinders, e.g. ozone, nitrogen dioxide and ammonia, increased in the early 1990s. The several operators of national and (inter-)cantonal networks responsible for the enforcement of the air pollution control legislation, unified in an association called Cercl'air, became increasingly aware of the importance of quality assurance issues based on intense political debate about costly and sometimes restrictive cantonal actions referring to air pollution measurement results. ${ }^{9]}$ Consequently METAS began to offer calibration services for ozone calibrators and for $\mathrm{NO}$ and $\mathrm{NO}_{2}$ transfer standards used within the networks in 1993 on a voluntary basis. In the past five years, the average number of yearly calibrations for ozone generators was about 30 instruments. The yearly demand for calibrations based on dynamically prepared gas mixture standards of reactive analytes is five to eight, as yet low but also increasing.

The new service to measure the retention efficiency of zero gas generators under close real conditions with trace analytical methods attracts increasing interest for the quality assurance of the ground level air measurements.

\section{Basic Aspects of Gas Metrology}

Gas analytical measurements can be divided into two ranges according to the concentration range: emission applications and the ambient air or immission tasks, where also workplace atmosphere is included. We can roughly assign the emission range to a amount of substance fraction of $>1 \mu \mathrm{mol} \cdot \mathrm{mol}^{-1}$ without particularising the components. The ambient air range would then cover the range below $1 \mu \mathrm{mol} \cdot \mathrm{mol}^{-1}$.

When indicating ranges the first very important question arises about the quantity to be used. Should it be a concentration and if yes, is it a amount of substance concentration or a mass concentration? Would another quantity like volume concentration or amount of substance fraction not be much more convenient due to its independence of standard conditions? What is the difference between volume concentration and volume fraction? Unfortunately these questions are not always answered when legislative texts are prepared and when measurement results are published despite of the fact that there is a really clear and thoroughly elaborated article by Cvitaš in line with the current ISO standard 80000-9 that answers all these questions about quantities and units for chemical analysis.[10,11] In order to avoid possible misinterpretation of measurement results it is important to identify two critical areas of misunderstandings because measurement results are only comparable when they consist of a value and an uncertainty statement and when they refer to the same unit.[12]

The first area of concern where comparability is in danger is the correct and unambiguous use of quantities and their units. Even in most recent international standards for ozone and carbon monoxide measurement the internationally accepted nomenclature as cited above including the one specially for gas analysis in the relevant ISO standard 14912 expresses concentration of ozone or carbon monoxide in air in units of $\mathrm{nmol} \cdot \mathrm{mol}^{-1}$ or $\mu \mathrm{mol} \cdot \mathrm{mol}^{-1}$ respectively - a substance fraction - despite the fact that mass concentration in $\mu \mathrm{g} \cdot \mathrm{m}^{-3}$ or $\mathrm{mg} \cdot \mathrm{m}^{-3}$ is the quantity in which the limit and target values in the respective European directive are set. ${ }^{[2,13-15]}$

Another example of misleading use of a quantity is the mixing ratio widely used within the atmospheric chemistry community including the world meteorological organisation (WMO). Mixing is not really a meaningful attribute to a ratio quantity and even more important, it is not a ratio but a fraction, namely a volume or an amount of substance fraction when expressing the magnitude of a gaseous compound in the atmosphere in ppb or ppbv. ${ }^{[16]}$ This may look nitpicking when applied to the ambient air range but already for carbon dioxide the preparative uncertainties of highest quality reference materials are below the difference caused by the definitional differences of ratio quantities when aimed at fractions. [17] For oxygen the naturally occurring volume fraction, that is the oxygen volume divided by the total volume, is $209.46 \mathrm{~L} \cdot \mathrm{m}^{-3}$ but the volume ratio - the oxygen volume divided by the volume of all other gases - would then be about 299 $\mathrm{L} \cdot \mathrm{m}^{-3}$ causing a relative definitional difference of $43 \%$ !

The second area of possible misinterpretation is the omission of standard conditions for all concentration quantities. For most of the written standards mentioned, there is an indication of standard conditions, but for the reporting of measurement results it is often unclear to what standard conditions the volumes are referenced to. If there would be a uniformity of standard conditions there would be no real problem, but there are significant differences. Already in Switzerland we know at least four different standard conditions for gas analytical measurements. The first recommendation on immission measurement cited standard conditions to be $9{ }^{\circ} \mathrm{C}$ and 950 mbar, an attempt to establish a conventional 'Swiss mean condition'. ${ }^{[18]}$ Later revisions of the document corrected these conditions to $20{ }^{\circ} \mathrm{C}$ and $1013.25 \mathrm{hPa}$ in concordance with the four European daughter directives on ambient air monitoring. The relative difference between the mass concentration values referenced to these different conditions would already be $2.7 \%$. A special case is mentioned in the actual immission measurement recommendation for alpine stations above $1500 \mathrm{~m}$ a.s.1.[19] In this case reference conditions calculated from the long-time mean for temperature and pressure of the station should be applied. For emission measurements FOEN published also recommendations both citing $0{ }^{\circ} \mathrm{C}$ and $1013 \mathrm{hPa} \cdot{ }^{[20,21]}$ When reporting measurement results this variety of standard conditions in Switzerland and the even bigger variety in other countries and also within the international standardisation organisation makes it compulsory to indicate always the standard conditions of the volume in order to be able to calculate comparable concentration values.

Metrological principles that are valid not only to gas analysis consist of three main parts, the so-called metrological tripod: The first leg is the metrological traceability to realisations of a quantity - usually a derived quantity, whose input quantities are themselves traceable to realisations within the international system of units (SI) as it is described by DeBièvre. ${ }^{[22]}$ The definition of traceability implies the existence of an unbroken chain of calibrations of measurement results to a stated reference. ${ }^{[23]}$ Due to the sometimes underdeveloped hierarchy of reference standards in gas analysis - a prerequisite for a traceability chain - the chain cannot only be linear but also have horizontal links to other references of the same quality and therefore build a network structure. The evaluation of the measurement uncertainty takes into account the uncertainties accumulated by comparisons along the traceability chain to form the second leg. For a metrological service at METAS the evaluation is normally done according to the internationally accepted guide to the expression of uncertainty in measurement (GUM) or specific written standards. [24,25] Because there is always limited flexibility in applying the traceability principle and the uncertainty evaluations are based on models and assumptions that are most often not completely representative for the real measurement process it is essential to pay attention also to the third leg, the verification. Verification can be done by comparisons using different measurement means and/or different measurement methods realising or measuring the same specific quantity with at least the 
same or a lower uncertainty. Concordant results of comparisons would then be evidence for the reliable implementation of traceability to common standards, i.e. the international system of units (SI) and the realistic estimation of the measurement uncertainty.

To be able to fulfil the before-mentioned requirements for national standards, it is imperative to collaborate on an international level. Therefore METAS has been an active partner on the subcommittee 'Gases' of the EURAMET Technical Committee Metrology in Chemistry (METCHEM) from the beginning and later also in the Gas Working Group (GAWG) of the Consultative Committee for Amount of Substance (CCQM). [26,27] Several comparisons of the most important analytes have been accomplished and showed the high reliability of the gas analytical work at METAS as will be shown in the examples.

\section{Examples of Services and their Metrological Background}

The following examples show different possibilities of how to establish traceability of measurement results to the SI and the reasons for the respective choice. They should make clear that independent traceability to the SI does not imperatively mean that primary measurement methods or reference materials as defined by the CCQM are required. ${ }^{[28]}$ The resulting measurement uncertainties determine if a certain reference material or measurement instrument for reproducing or indicating composition values is fit for the intended purpose.

\subsection{Intercomparison of Gravimetric Gas Standards}

Gravimetric gas standards of stable analytes are produced in Switzerland by three manufacturers. They are accredited as calibration laboratories according to ISO standard 17025 and are using production procedures following ISO standard 6142.[29] The target relative expanded uncertainty for most applications that require the use of certified gas mixtures is about $1 \%$. In view of this moderate requirement, METAS decided to abstain from producing high level gravimetric standards for combustion gases itself. Instead highly reproducible and specific comparators in combination with an automated sampling system based on an electro polished low dead volume integrated gas component system (IGC) from Swagelok ${ }^{\circledR}$ are used. ${ }^{[8]}$ To analyse $\mathrm{CO}$ and $\mathrm{CO}_{2}$ a commercial modular GC is used with a unit that transforms the analytes into methane and a flame ionisation detector. The GC from

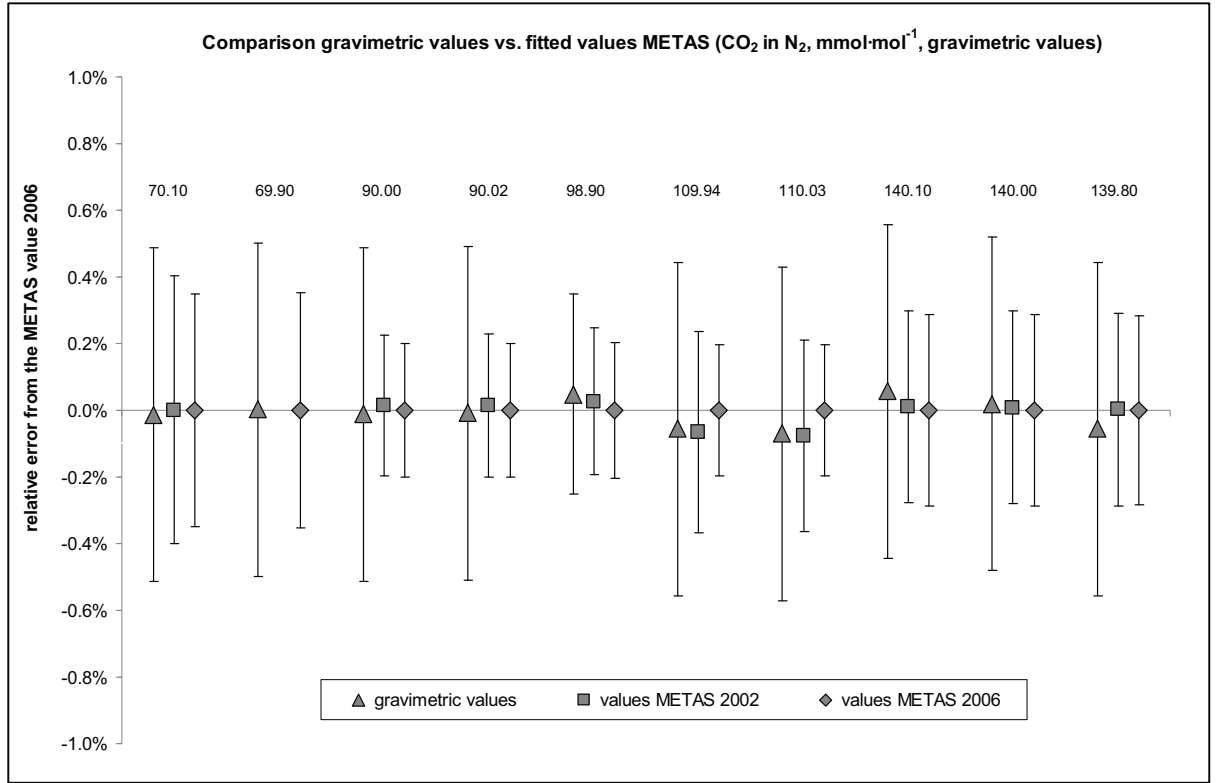

Fig. 1. Relative errors of gravimetric and former fitted values with reference to the actual calculated analysis function for the set of carbon dioxide mixtures forming the national standard in the given range. The uncertainty bars represent relative expanded uncertainties at a level of confidence of $95 \%$ (expansion coefficient $k=2$ ).

Orthodyne has a $1 \mathrm{~m}$ packed Porapak ${ }^{\mathrm{TM}} \mathrm{Q}$ column. In order to isolate the inlet system from ambient pressure fluctuations an electronic pressure regulation device ELPRESS from Bronckhorst is used. For propane mixtures the methaniser is not used. For nitrogen monoxide mixtures, the inlet system is coupled to a chemiluminescence instrument CLD 700 EL from ECO PHYSICS, and for oxygen mixtures a paramagnetic instrument SIEMENS Oxymat $6 \mathrm{E}$ is used as the comparison device. The sampling system and the analysers are fully automated with LabView ${ }^{\circledR}$ programs and TestStand Sequences.

For each of the analytes mentioned a set of existing mixtures is regularly compared with newly produced mixtures in order to renew the set of mixtures because there is a limited lifetime of the cylinders. This comparison can be performed with a reproducibility of $<0.05 \%$ relative to all the analytes. Supposing that the individual mixtures from the Swiss manufacturers together with mixtures from Van Swinden Laboratory (VSL) and the National Physical Laboratory (NPL) as leading metrology institutes are independent realisations of amount of substance fractions traceable to mass and purity, the comparison conducted according to ISO 6143 can be used to establish a calibration function for the whole range of the set of mixtures. ${ }^{[25]}$ This calibration function can be used to calculate new reference values for every mixture with somewhat lower uncertainties as it is done also in so-called CCQM preparative comparisons. ${ }^{[30-32]}$ The calculated reference values attributed to the mixtures are then no longer independent but correlated to the values of all other mixtures used to establish the respective analysis function. In this case we can speak of an almost horizontal traceability that guarantees some redundancy and a broad support of the realised analysis function. This has the advantage that every non-concordance of an examined gas mixture with the whole set of mixtures will be detected and the national standard is not dependent on only one mixture that may be faulty for whatever reason.

In Fig. 1 an example of the relative errors of gravimetric and former fitted values with reference to the actual analysis function is given for the set of carbon dioxide mixtures. It can be seen that relative differences between consecutive comparisons is about a factor of 5 to 20 lower than the evaluated uncertainty according to ISO standard 6143 and therefore a sufficient stability over several years can be taken for granted. ${ }^{[25]}$ The given uncertainty is itself a factor of 2 to 3 lower than the uncertainty normally required by reference gas mixture users.

The verification of all these sets of reference gas mixtures is on the one hand a means of control by using mixtures produced by other national metrology institutes and on the other hand participation in international key and supplementary comparisons. METAS participated in projects in the framework of EURAMET (formerly EUROMET) and CCQM with acronyms K3, P23, P50a, and not yet published K51. ${ }^{[30,33-35]}$ All these comparisons show very satisfactory results providing evidence for a successful verification of the measurement results issued by METAS. 
Due to this activity the calibration certificates for all the published calibration capabilities are mutually recognised by all the signatories of the CIPM Mutual Recognition Arrangement. ${ }^{[36]}$

\subsection{Calibration of Ozone Instruments}

Ozone cannot be stored in pressurised cylinders due to its reactivity. Therefore a different approach had to be found to set up a national standard in order to be able to disseminate reliable values of amount of substance fractions of ozone in air. This approach was to establish a UV photometer as a primary standard instrument combined with a highly stable ozone generation device. In 1993 METAS was the first European metrology institute to buy the Standard Reference Photometer (SRP) no 14, a dual cell instrument manufactured by the National Institute of Standards and Technology (NIST) and well explained by Viallon. ${ }^{[37]}$ Shortly afterwards the backup instrument SRP18 was acquired on one hand to have some redundancy and on the other hand to be able to investigate the principle and do further development. A crucial prerequisite for the proper operation of the two instruments was the installation of a zero air generation facility that fulfils the requirements set in the later published European standard 14625.[13] The measurement equation implemented in all SRPs is derived from the Beer-Lambert and ideal gas laws. The amount of substance fraction of ozone in air is calculated from Eqn. (1)

$$
x\left(O_{3}\right)=\frac{-1}{2 \cdot \alpha_{x} \cdot L_{o p t}} \frac{T}{T_{s}} \frac{p_{s}}{p} \cdot \ln (D)
$$

where $\alpha_{x}$ is the linear absorption coefficient at $253.65 \mathrm{~nm}$ and at standard temperature $\left(T_{s}\right)$ and pressure $\left(p_{s}\right)$. Its value was chosen to be the molecular absorption cross section $\sigma$ of $1.1476 \cdot 10^{-21} \mathrm{~m}^{2}$ recalculated according to Eqn. (2).

$$
\alpha_{x}=\sigma \cdot \frac{N_{A} \cdot p_{s}}{R \cdot T_{s}}
$$

resulting in $\alpha_{x}=308.32 \mathrm{~cm}^{-1}$. ${ }^{[38]}$ Its relative standard uncertainty of $1.06 \%$ is the predominant component and it would be a challenge for the future to re-evaluate or perhaps calculate a more accurate value by ab initio methods. ${ }^{[37]}$ The optical length $L_{o p}$ is taken as the mean geometrical length of the two cells knowing that the optical length for the actual design of cells can be longer due to beam divergence and internal reflexion. This effect is not corrected but to be in-

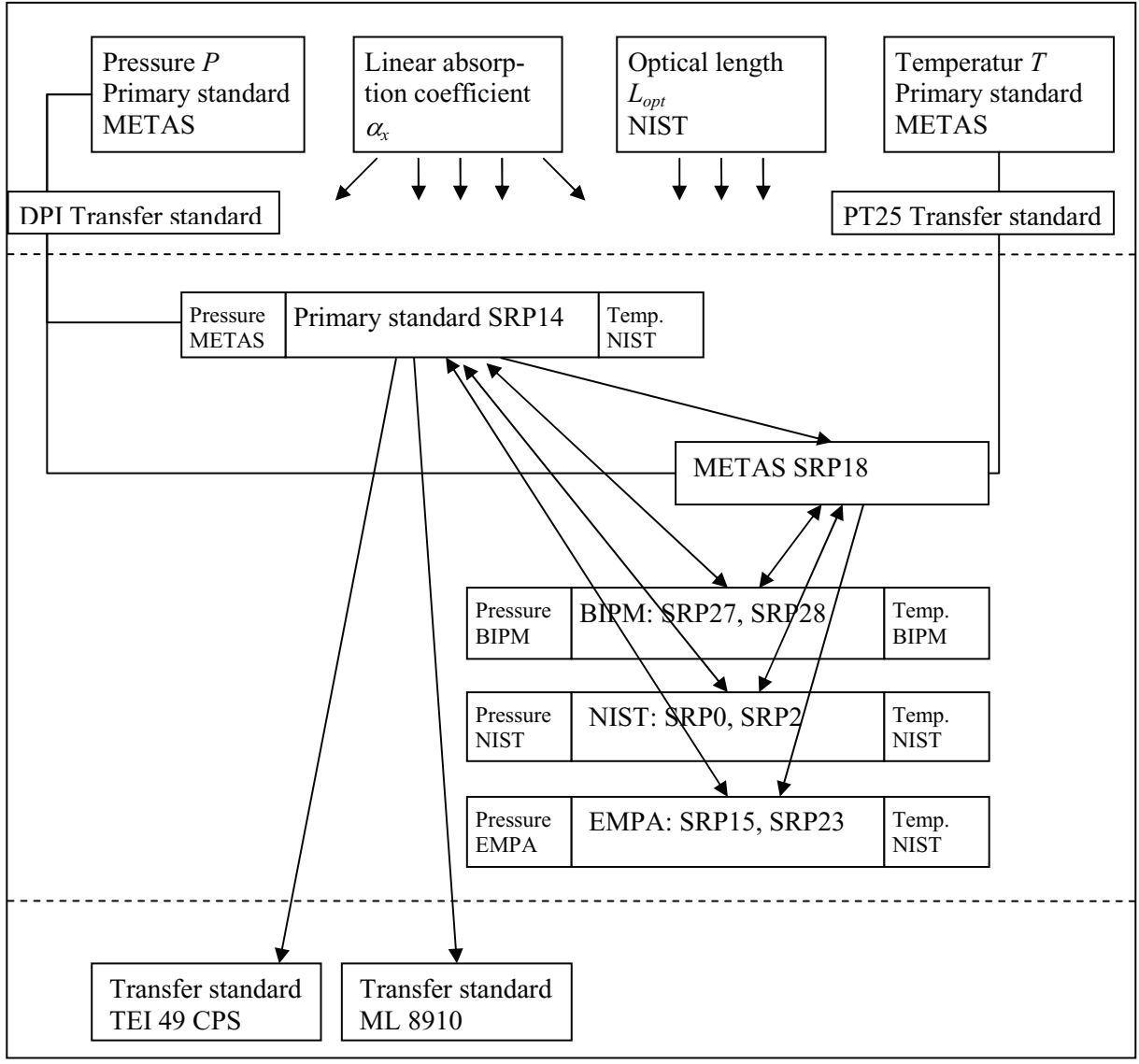

Fig. 2. Traceability scheme of the primary realisation of amount of ozone fractions in air and dissemination to transfer standards at METAS. The input quantities pressure and temperature are traceable via different paths to independent realisations traceable to the SI. The optical length is measured at NIST and the same linear absorption coefficient is chosen by convention from literature for all photometers.

cluded in the uncertainty budget. Multipath reflexions are best possibly eliminated by using tilted cell windows. For the gas temperature $T$ and the gas pressure $p$ in the cells it is essential to measure as close as possible to the cells and to include also the possible temperature and pressure gradients into the uncertainty evaluation. $D$ is the product of the transmittances of the two cells with transmittance defined as the ratio of the light intensity measured with ozonized air to the light intensity measured with zero air. The standard deviation of $D$ is determined experimentally. All these input quantities have their own traceability to higher standards as shown in Fig. 2 except for $D$ which is a relative quantity only contributing to the variance of the output quantity.

When calibrating 'ozone calibrators' the standard deviation and the resolution of a device under test also contribute to the best measurement capabilities. The actual uncertainty budget for the amount of ozone fraction of the SRP 14 is summarised in Table 1. When expressing the best measurement capability we can then summarise the absolute and the relative contributions together with the resolution $\left(0.1 \mathrm{nmol} \cdot \mathrm{mol}^{-1}\right)$ and the standard deviation $\left(0.2 \mathrm{nmol} \cdot \mathrm{mol}^{-1}\right)$ of a best existing de- vice as a amount of substance fraction dependent expanded uncertainty (Eqn. (3)):

$$
\begin{aligned}
U\left(x_{O_{3}}\right)= & \sqrt{\left(1.1 \cdot \mathrm{nmol} \cdot \mathrm{mol}^{-1}\right)^{2}+\left(0.022 \cdot x_{O_{3}}\right)^{2}} \\
& x_{O_{3}} \text { in } \mathrm{nmol} \cdot \mathrm{mol}^{-1}
\end{aligned}
$$

The national standard for ozone has to be verified in the same as gas mixture standards. The verification was initially done by performing bilateral comparisons with NIST and other national laboratories. For that purpose one of the participants had to travel with a suitable transfer standard that was in the case of NIST the SRP0. In 2000 the EUROMET project 414 with 15 participating laboratories was completed and the outcome of this comparison was a concordance of the participants within $2.5 \%$ rel. and some detected problems with a drifting transfer standard. ${ }^{[39]}$ Three years later the Bureau International des Poids et Mesures (BIPM) took an initiative to compare national ozone standards on a worldwide scale with 23 participants, some using gas phase titration methods (GPT). The results and the findings were published and as a consequence the elimination of the detected biases for tempera- 
Table 1. Uncertainty budget for the amount of ozone fraction in air measured by the national primary UV-photometer SRP14

\begin{tabular}{|c|c|c|c|c|c|c|}
\hline \multirow{2}{*}{$\begin{array}{l}\text { Input } \\
\text { quantity (y) }\end{array}$} & \multicolumn{3}{|c|}{ Uncertainty $u(y)$ for SRP 14 (METAS) } & \multicolumn{2}{|r|}{$\begin{array}{l}\text { Sensitivity } \\
\text { coefficient }\end{array}$} & \multirow{2}{*}{$\begin{array}{l}\text { contribution to } u(x) \\
\left|c_{i}\right| \cdot u(y) \\
\mathrm{nmol} \cdot \mathrm{mol}^{-1}\end{array}$} \\
\hline & Source & $\begin{array}{l}\text { Distribution } \\
\text { type }\end{array}$ & $\begin{array}{l}\text { Standard } \\
\text { Uncertainty }\end{array}$ & $\begin{array}{l}\text { standard } \\
\text { uncertainty } u(y)\end{array}$ & $c_{i}=\frac{\partial x}{\partial y}$ & \\
\hline \multirow{3}{*}{$\begin{array}{l}\text { Optical Path } \\
\text { Length } L_{o p t}\end{array}$} & Measurement Scale & Rectangular & $0.0006 \mathrm{~cm}$ & \multirow{3}{*}{$0.116 \mathrm{~cm}$} & \multirow{3}{*}{$-\frac{x}{L_{o p t}}$} & \multirow{3}{*}{$1.30 \cdot 10^{-3} \cdot x$} \\
\hline & Repeatability & Normal & $0.004 \mathrm{~cm}$ & & & \\
\hline & Divergence & Rectangular & $0.115 \mathrm{~cm}$ & & & \\
\hline \multirow{2}{*}{ Pressure $p$} & Sensor incl. calibration & Normal & $0.015 \mathrm{kPa}$ & \multirow{2}{*}{$0.023 \mathrm{kPa}$} & \multirow{2}{*}{$-\frac{x}{p}$} & \multirow{2}{*}{$2.3 \cdot 10^{-4} \cdot x$} \\
\hline & Difference between cells & Rectangular & $0.018 \mathrm{kPa}$ & & & \\
\hline \multirow{2}{*}{ Temperature $T$} & Sensor incl. calibration & Normal & $0.05 \mathrm{~K}$ & \multirow{2}{*}{$0.13 \mathrm{~K}$} & $x$ & \multirow{2}{*}{$4.4 \cdot 10^{-4} \cdot x$} \\
\hline & Gradient over cells & Rectangular & $0.115 \mathrm{~K}$ & & $T$ & \\
\hline \multirow{2}{*}{$\begin{array}{l}\text { Ratio of intensities } \\
D\end{array}$} & Scaler resolution & Rectangular & $6 \cdot 10^{-6}$ & \multirow{2}{*}{$1.2 \cdot 10^{-5}$} & $1 \quad T \cdot p_{s}$ & \multirow{2}{*}{0.24} \\
\hline & Repeatability & Normal & $1 \cdot 10^{-5}$ & & $2 \alpha_{x} L_{o p t} \quad T_{s} \cdot p$ & \\
\hline $\begin{array}{l}\text { Lin. Absorption } \\
\text { coefficient } \alpha_{x}\end{array}$ & Hearn value & Normal & $3.27 \mathrm{~cm}^{-1}$ & $3.27 \mathrm{~cm}^{-1}$ & $-\frac{x}{\alpha_{x}}$ & $1.06 \cdot 10^{-2} \cdot x$ \\
\hline
\end{tabular}

ture and optical length was the next effort in order to improve the concordance that was already at a level of $1.5 \%$ rel. with some exceptions including GPT.[40] The upgrade of the Swiss SRPs including those from the Swiss Federal Laboratories for Materials Testing and Research (EMPA) and SRP26 from the Austrian Umweltbundesamt (UBA) to eliminate the biases took place in September 2007 and was reported in METinfo. ${ }^{[41]}$ The concordance between the five upgraded SRPs against SRP0 was found to be within $0.12 \%$ rel. The most recent comparison that has the status of a key comparison conducted also by the BIPM is an on-going activity and takes place in phases of two years. METAS performed its comparison against SRP27 that acted as a conventional standard in July 2008. The METAS result is published in METinfo and the final report of the comparison in Metrologia. ${ }^{[42,43]}$ In all comparisons SRP14 never deviated from the reference value larger than the stated uncertainty.

\subsection{Preparation of Dynamic Reference Gas Mixtures}

In the third example a generation method represents the national standard rather than a set of reference materials or a measuring instrument. The permeation method as standardised in the specific ISO standard 6145-10 is able to deliver dynamically generated concentrations of reactive and volatile compounds in the $\mathrm{nmol} \cdot \mathrm{mol}^{-1}$ range that are traceable to the SI via the national standards for mass, temperature, time and flow according to the traceability scheme in Fig. 3.[44] The directly gener- ated amount of substance fraction $x_{\mathrm{B}}$ of an analyte in the dilution gas on a magnetic suspension balance as described by Zickert and Quintilii is calculated as in Eqn. (4):

$$
x_{B}=\frac{q_{m}(B)}{q_{v}(d i l)} \cdot \frac{V_{m}(d i l)}{M(B)}+x_{B}(d i l)
$$

where $q_{m}(B)$ is the mass flow of analyte $B$ through the permeation membrane at a defined temperature and $q_{V}(d i l)$ is the referenced volume flow of the dilution gas. ${ }^{[45,46]}$ The molar volume of the dilution gas at reference conditions $V_{m}(d i l)$ and the molar mass of the analyte $M(B)$ are used to transform the mass concentration formed by the first ratio into an amount of substance fraction. The amount of substance fraction of the analyte in the dilution gas $x_{B}(d i l)$ is in many cases near zero or at least below the detection limit and therefore taken as zero with a related uncertainty that can be substantial for very low fractions. According to the same principle it is also possible to generate gas mixtures based on calibrated permeation devices with an external permeation oven providing a controlled dilution gas flow. When using this technique it is essential to reproduce the temperature during the permeation device calibration in the permeation oven with high accuracy and to calibrate the permeator not only before but also after use in order to be able to compensate for possible drifts. Temperature deviations or corrections due to temperature deviations as well as drift cor- rection create uncertainty contributions in addition to the direct method.

The big advantage of the permeation method is the direct generation of amount of substance fractions down to the low $\mathrm{nmol} \cdot \mathrm{mol}^{-1}$ range in one step and the versatility to change the amount of substance fractions by varying the dilution flow very quickly. These changes have to be followed by analysing instruments that are adapted to the measurement ranges and very specific to the analytes in order to detect stable operation and also possible damages to permeation devices that cause unstable permeation. Therefore METAS operates a chemiluminescence detector 42i TL by Thermo for nitrogen oxides, a photoacoustic infrared photometer TGA310 XO by Omnisens for ammonia and a GC amosBTX 5000 with an adsorptionthermodesorption step by Analytical Monitors. A synopsis of the actual calibration capabilities at METAS is given in Table 2.

Unfortunately only a few comparisons with other institutes and other reference methods have been performed. The results of the most recent international key comparison on ammonia in nitrogen with the acronym CCQM-K46 are not yet published. In general they show that multistep gravimetric preparation of reactive gases comes to the limit of being a primary method, because the assumption that what is put into a cylinder is the same as that what comes out of a cylinder, is no longer justified. Not yet well understood adsorption and desorption effects that are dependent on the cylinder inner surface treatment and of course temperature and pressure play an 


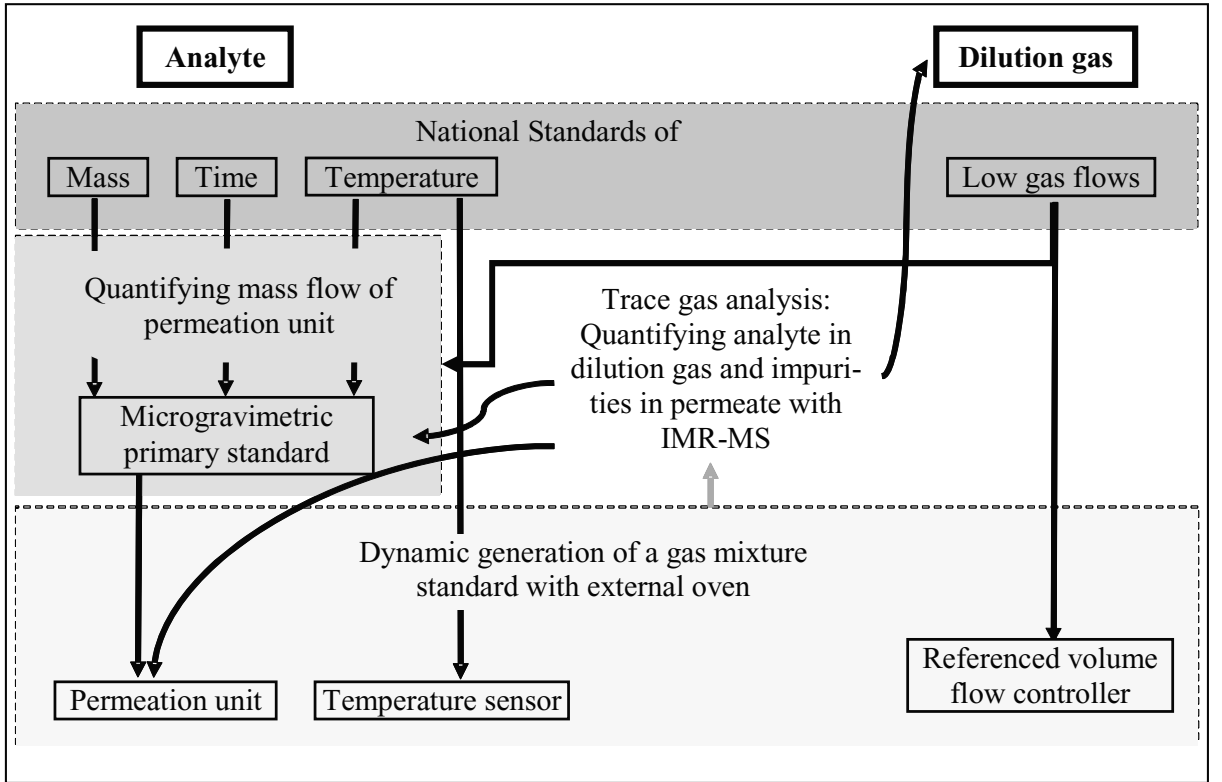

Fig. 3. General traceability scheme of the permeation method realised as a primary microgravimetric gas mixture generator based on a magnetic suspension balance. The lower part describes the dynamic generation with an independent external permeation oven. To quantify the mass flow of the analyte, temperature and dilution gas volume flow are only influencing condition quantities, whereas for the generation in a permeation oven, temperature is a direct input quantity to calculate the mass flow of the analyte and together with the dilution gas flow the amount of substance fraction.

important role and can lead to significant changes in the amount of substance fraction and also to losses from one step of preparation to the next.

\section{Outlook and Future Needs}

METAS will continue to underpin the calibration and measurement capabilities in the framework of the CIPM-Mutual Recognition Arrangement for selected analytes or methods. The dynamic generation of gas mixtures for the ambient concentration range will be a focus for future developments and the permeation method will be supplemented by the volumetric dilution method ISO standard 6145-7 and the diffusion method ISO standard 61458 to broaden the range of analytes and to profit from the experiences with the permeation method. ${ }^{[47,48]}$ The prerequisites for this effort are continuous high accuracy calibration services for gas flows below 10 $\mathrm{dm}^{3} \mathrm{~min}^{-1}$ and a trace gas analysis that is capable of measuring the required concentrations of analytes in the dilution gas. ${ }^{[49,50]}$ METAS will also initiate comparisons in the immission measuring range by means of a highly stable mobile permeation oven for which all input quantities can easily be made traceable to national standards. Because some instabilities of nitrogen dioxide standards have been reported by Brunner, a mobile oven currently under development could also be used as a transfer standard in national round robin tests or international comparisons. ${ }^{[1]}$

Besides metrological services, education and consultancy for subjects like uncertainty evaluation, quality assurance or validation are continuous tasks that METAS is prepared to accomplish.

\section{Conclusion}

METAS offers a range of services in the field of gas analysis that fulfil the metrological requirements of traceability, known uncertainty and external verification. The three mentioned examples show that there are different possibilities to establish references for gas composition quantities. The choice of the realisation of a national standard is very much influenced on one hand by the requirements from a related market and on the other hand by the simple feasibility and the measurement capabilities required for the realisation of a reference

Table 2. METAS calibration capabilities with the microgravimetric primary standard based on a magnetic suspension balance and the respective relative expanded uncertainties.

\author{
Gas mixture and/or measuring \\ instrument \\ $\mathrm{NO}_{2}$ gas mixture \\ $\mathrm{NH}_{3}$ gas mixture \\ Gas mixtures containing fractions \\ of benzene, toluene, ethylbenzene, \\ $m$-xylene, o-xylene \\ NO gas mixture
}

$\mathrm{NO}_{x}$ measuring instrument

$\mathrm{NH}_{3}$ measuring instrument

BTEX measuring instrument

$\mathrm{NO}_{2}, \mathrm{NH}_{3}, \mathrm{SO}_{2}$, benzene, toluene, ethylbenzene, $m$-xylene, $o$-xylene permeation units
Measurand

Amount of substance fraction

Amount of substance fraction

Amount of substance fraction

Amount of substance fraction

$\mathrm{NO}$ and $\mathrm{NO}_{2}$ amount of substance fractions

Amount of substance fraction

Amount of substance fractions

Mass flow through membrane

\section{Notes}

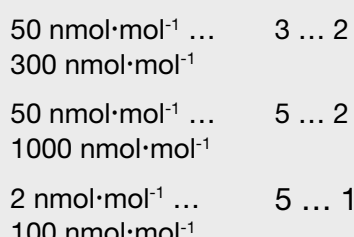

$2 \ldots 1.2$

NO: $2.5 \ldots 1.5$

$\mathrm{NO}_{2}: 3 \ldots 2$

$5 \ldots 2$

$5 \ldots 1$

$5 \ldots 0.5$
Binary or multi-component gas mixtures

Binary or multi-component gas mixtures

In addition: other easily condensable substances 
method. As in many other fields of metrology in chemistry a hierarchy of measurement standards is being established in the field of gas analysis. The improvements of concordance on the field level and the very small number of complaints related to the measurement quality for legal applications demonstrate that the effort for reliable standards is worthwhile.

\section{Acknowledgments}

The author particularly thanks all the current and former members of the gas analytical laboratory from METAS for their advice and contributions. Hanspeter Andres (METAS) and Ulrich Feller (METAS) are warmly acknowledged for their support and inspiring discussions

Received: June 25, 2009

[1] J. Brunner, Ringkontrolle 2007, Umwelt- und Gesundheitsschutz Zürich (UGZ) im Auftrag Cercl'Air und BAFU, Zürich, 2008.

[2] Directive 2008/50/EC of the European Parliament and of the Council of 21 May 2008 on ambient air quality and cleaner air for Europe.

[3] Luftreinhalte-Verordnung SR 814.318.142.1, http://www.admin.ch/ch/d/sr/8/a814_318_ 142 1.html.

[4] Abgaswartungsverordnung SR 741.437, http:// www.admin.ch/ch/d/sr/c741_437.html.

[5] Abgasprüfgeräteverordnung SR 941.242, http:// www.admin.ch/ch/d/sr/chrono/1985/c15019. html.

[6] Weisungen über Abgasmessgeräte für Feuerungsanlagen, http://www.metas.ch/w242.3d. $p d f$.

[7] Bundesamt für Umwelt, Wald und Landschaft (BUWAL), Empfehlungen zur Messung der Abgase von Feuerungen für Heizöl 'Extra leicht' oder Gas, Bern, 2005.

[8] J.-F. Perrochet, 'Gaz de référence pour le mesurage d'émission de polluants: principes et pratique', OFMETInfo 1994, 2, 6 .

[9] Schweizerische Gesellschaft der LufthygieneFachleute, www.cerclairch.

[10] T. Cvitaš, Metrologia 1996, 33, 35.

[11] ISO 80000-9: 2009, 'Quantities and Units Physical Chemistry and Molecular Physics'.

[12] P. DeBièvre, Accred. Qual. Assur. 2006, 11, 487.

[13] EN 14625: 2005, 'Ambient air quality Standard method for the measurement of the concentration of ozone by ultraviolet photometry'.

[14] EN 14626: 2005, 'Ambient air quality - Standard method for the measurement of the concentration of carbon monoxide by nondispersive infrared spectroscopy'.

[15] International Organisation for Standardisation, ISO 14912: 2003/Cor 1: 2006, 'Gas analysis Conversion of gas mixture composition data'.

[16] L. A. Barrie, G. Braathen, personal communication, 29th march 2006.

[17] R. M. Wessel, A. M. H. van der Veen, P. R. Ziel, P. Steele, R. Langenfelds, M. van der Schoot, D. Smeulders, L. Besley, V. Smarçao da Cunha, Z. Zhou, H. Qiao, H. J. Heine, B. Martin, T. Macé, P. K. Gupta, E. Amico di Meane, M. Sega, F. Rolle, M. Maruyama, K. Kato, N. Matsumoto, J. Seog Kim, D. Min Moon, J. Bok Lee, F. Rangel Murillo, C. Ramírez Nambo, V. M. Serrano Caballero, M. de Jesús Avila Salas, A. Pérez Castorena, L. A. Konopelko, Y. A. Kustikov, A. V. Kolobova, V. V. Pankratov, O. V. Efremova, S. Musil, F. Chromek, M. Valkova, M. J. T. Milton, G. Vargha, F. Guenther, W. R.
Miller, A. Botha, J. Tshilongo, I. S. Mokgoro and N. Leshabane, Metrologia 2008, 45, Techn. Suppl.; doi: 10.1088/0026-1394/45/1A/08011.

[18] BUWAL, Immissionsmessempfehlung, 1990, Art. 523.

[19] BUWAL: Immissionsmessempfehlung 1.1 . 2004.

[20] BUWAL: Empfehlungen über die Emissionsmessung von Luftfremdstoffen bei stationären Anlagen 1996, Stand Mai 2001.

[21] BUWAL: Empfehlungen zur Messung der Abgase von Feuerungen für Heizöl 'Extra leicht' oder Gas 1996, Stand Februar 2002.

[22] P. DeBièvre, P. D. P. Taylor, Metrologia 1997, 34, 67.

[23] BIPM, IEC, IFCC, ILAC, ISO, IUPAC, IUPAP and OIML: JCGM 200, 2008, (E/F) 'International vocabulary of metrology - Basic and general concepts and associated terms (VIM)'.

[24] International Organisation for Standardisation, ISO/IEC Guide 98-3: 2008, 'Uncertainty of measurement - Part 3: Guide to the expression of uncertainty in measurement'.

[25] International Organisation for Standardisation, ISO 6143: 2001, 'Gas analysis - Comparison methods for determining and checking the composition of calibration gas mixtures'.

[26] EURAMET (European Association of National Metrology Institutes), technical committee Metrology in Chemistry TC-MC, http://www.

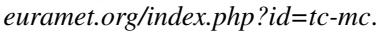

[27] BIPM (Bureau International des Poids et Mesures, Paris), Comité Consultatif pour la Quantité de Matière, CCQM: http://www.bipm. org/en/committees/cc/ccqm/.

[28] BIPM, Comité Consultatif pour la Quantité de Matière, Report of 1st meeting, 1995.

[29] International Organisation for Standardisation, ISO 6142:2001, 'Gas analysis - Preparation of calibration gas mixtures, Gravimetry method', Second edition, 2001(E).

[30] A. M. H. van der Veen, J. I. T. van Wijk, R. J. Oudwater, R.-J. Heemskerk, J.-F. Perrochet, F. R. Guenther, L. Besley, H.-J. Heine, A Marchal, T. Macé, K. Kato, J. S. Kim, M. C. A. Perez Castorena, A. Rakowska, I. Castanheira L.A. Konopelko, Y. A. Kustikov, V. Pankratov, S. Musil, I. J. Uprichard, P. T. Woods, M. J. T. Milton, International comparison CCQM-P23: 'Carbon monoxide in nitrogen gravimetry comparison', internal report CCQM GAWG, Zoeterwoude, The Netherlands, 2000.

[31] A. M. H. van der Veen, F. N. C. Brinkmann, M Arnautovic, L. Besley, H.-J. Heine, T. Lopez Esteban, M. Sega, K. Kato, J. Seog Kim, A. Perez Castorena, A. Rakowska, M. J. T. Milton, F. R. Guenther, R. Francey and E. Dlugokencky, Metrologia 2007, 44, Techn. Suppl.; doi: 10.1088/0026-1394/44/1A/08002 .

[32] R. I. Wielgosz, M. Esler, J. Viallon, P. Moussay, S. Hyub Oh, B. Moon Kim, A. Botha, J. Tshilongo, I. S. Mokgoro, M. Maruyama, T. Macé, C. Sutour, V. Stovcík, M. Valková, S. Musil, A. Pérez Castorena, V. Serrano Caballero, F. Rangel Murillo, L. A. Konopelko, Y. A. Kustikov, V. V. Pankratov, E. V. Gromova, W. J. Thorn, F. R. Guenther, D. Smeulders, G. Baptista, F. Dias, R. M. Wessel, G. Nieuwenkamp and A. M. H. van der Veen, Metrologia 2008, 45, doi: 10.1088/00261394/45/1A/08002.

[33] A.M.H. van der Veen, G. Nieuwenkamp, R. Oudwater, R.M. Wessel, J. Novak, J-F. Perrochet, A. Ackermann, A. Rakowska, L. Cortez, F. Dias, L. Konopelko, Y. Kustikov, C. Sutour, T. Macé, M.J.T Milton, I.J.Uprichard, P.T. Woods, J. Walden, M.T. Lopez Esteban, International comparison EUROMET.QM-K1c, 2003, http://www.bipm.org/utils/common/pdf/final_reports/QM/K1/EUROMET.QM-K1.c.pdf
[34] A. M. H. van der Veen, Metrologia 2002, 39, 121; doi: 10.1088/0026-1394/39/1/18.

[35] M. Milton, A. Perez, M. Maruyama, J. Novak, J. Walden, A. Borowiak, F. Lagler, J. Seog Kim, T. Macé, C. Sutour, F. Guenther, A. van der Veen, G. Nieuwenkamp, G. Vargha, G. Leggett, A. Medem, V. Stummer, L. Konopelko, Y. Kustikov, N. Pivovarova. F. Dias, M. Quintili, M. Froehlich, International key comparison CCQM-K26a and pilot study CCQM-P50a (NO), internal report CCQM, GAWG, NPL, Teddington (United Kingdom), 2006, http:// kcdb.bipm.org/appendixB/appbresults/ccqmk26.a/ccqm-k26.a_final_report.pdf.

[36] BIPM, Mutal Recognition Arrangement, http:// www.bipm.org/en/cipm-mra/.

[37] J. Viallon, P. Moussay, J. E. Norris, F. R. Guenther and R. I.Wielgosz, Metrologia 2006, $43,441$.

[38] A. G. Hearn, Proc. Phys. Soc. 1961, 78, 932.

[39] B. P. Sweeney, M. J. T Milton, D. M. Butterfield and P. T. Woods, 'Intercomparison of National Ozone Primary Standards', Report on EUROMET project 414, 2002.

[40] J. Viallon, P. Moussay, M. Esler, R. Wielgosz, W. Bremser, J. Novák, M. Vokoun, A. Botha, M. Janse Van Rensburg, C. Zellweger, S. Goldthorp, A. Borowiak, F. Lagler, J. Walden, E. Malgeri, M. P. Sassi, P. Morillo Gomez, R. Fernandez Patier, D. Galan Madruga, J.C. Woo, Y. D. Kim, T. Macé, C. Sutour, A. Surget, B. Niederhauser, D. Schwaller, B. Frigy, I. Györgyné Váraljai, S. Hashimoto, H. Mukai, H. Tanimoto, H. P. Ahleson, A. Egel $\varnothing v$, N. Ladegard, L. Marsteen, K. Tørnkvist, F. R. Guenther, J. E. Norris, T. L. Hafkenscheid, M. M. van Rijn, P. Quincey, B. Sweeney, S. Langer, B. Magnusson, J. Bastian, V. Stummer, M. Fröhlich, A. Wolf, L. A. Konopelko, Y. A. Kustikov and D. V. Rumyanstev, Metrologia 2006, 43, Techn. Suppl.; doi: 10.1088/00261394/43/1A/08010.

[41] D. Schwaller, B. Niederhauser, 'Upgrades verbessern Ozonmessgeräte', METinfo $\mathbf{2 0 0 7}$ 14(3), 22.

[42] B. Niederhauser, 'Nationale Ozon-Normale stimmen immer besser überein', METinfo 2009, 16(1), 17.

[43] J. Viallon, P. Moussay, R. Wielgosz and B. Niederhauser, Metrologia 2009, 46, Techn. Suppl.; doi: 10.1088/0026-1394/46/1A/08016.

[44] International Organisation for Standardisation, ISO 6145-10, 2002, 'Gas analysis - Preparation of calibration gas mixtures using dynamic volumetric methods - Part 10: Permeation method'.

[45] D. Zickert, 'Die schwebende Ampulle', METinfo 2002, 9(3), 8.

[46] M. Quintilii, H.-P. Haerri, 'Preparation of SItraceable calibration gas mixtures by using permeation units', poster presentation, GAS 2007 $4^{\text {th }}$ Gas Analysis Symposium \& Exhibition, February 2007

[47] International Organisation for Standardisation, ISO 6145-7: 2009, 'Gas analysis - Preparation of calibration gas mixtures using dynamic volumetric methods - Part 7: Thermal mass flow controllers'.

[48] International Organisation for Standardisation, ISO 6145-8: 2005, 'Gas analysis - Preparation of calibration gas mixtures using dyna mic volumetric methods - Part 8: Diffusion method'.

[49] METAS, small gas flows, www.metas.ch/lowflow.

[50] METAS, trace element analysis of gas, $w w w$. metas.ch/trace. 